\title{
Reform Attempts in Teaching Methods on Metallurgical Technology Professional English
}

\author{
Yan Liu ${ }^{1, a}$, Yan Wang ${ }^{1, b}$, Liying Li ${ }^{1, \mathrm{c}}$, Lina Sun ${ }^{1, \mathrm{~d}}$ \\ ${ }^{1}$ Metallurgy engineering Institute, Liao Ning Institute of Science Technology, Benxi, 117004, China \\ aemail: Liuyan_425@sina.com, bemail:wy_yanzifei2003@163.com, cemail: muzililiying@163.com, \\ demail: linasunwu@163.com (Corresponding author)
}

Keywords: Professional English; Teaching Methods; Multiple Intelligences Theory; Multimedia; Task-based Approach

\begin{abstract}
According to the problem that the intelligence is not high of the soccer robot, using the mechanical theory as a guide, making some mechanical analyses and calculations on the pressure and transmutation states of chip kick mechanics, and conducting optimal design too, then making the structure of chip kick mechanics more and more rationalization. Experiments show that the new soccer robot controller features a quick response and high servo rigidity, and provide a kind of method for improving and perfecting the soccer robot control system, at the same time, filling the needs of producing.
\end{abstract}

\section{Introduction}

Professional English is a language subsystem which can achieve a communicative function in a certain professional field. Compared with general English, the vocabulary, common sentence patterns and language style and so on of professional English have its specificity and professional. This characteristic is especially obvious in metallurgical technology professional English.

The traditional professional English teaching mainly to teachers in the teaching, the teacher read the text and then translates it, students in a passive absorption status. The classroom teaching activities are centered on teachers and textbooks. It is bad for cultivating students' English comprehensive application ability, especially listening and speaking skills.

In recent years, domestic institutions of higher learning made full use of multimedia technology, adopt new teaching modes to improve the original single classroom teaching mode which mainly relied on teachers [1], and the students' abilities of individualized learning and autonomous learning are improved.

Any teaching reforms must be based on a certain theory. The theory of multiple intelligences has been widely applied in the teaching of primary and secondary schools. And the college teaching practice proves that the theory at least has important guiding significance to professional English teaching.

The multiple intelligences theory was put forward by developmental psychologist Gadner [2-3], the professor of Harvard. This theory held that the intelligence is the individual ability to solve practical problems, the ability to produce or create the effective product which having social value. The Frames of Mind includes of langue, logic (mathematics), vision (space), music (rhythm), body (sport), interpersonal (communication), self-examination, natural observer, exist. Gardner believes that everyone has the nine basic intelligences; their intelligence will be shown individual differences based on the combination of different basic intelligences. The starting point of education is not the person how clever but the teachers how to make students become smart.

Language is part of the cultural system and different languages have different cultural connotations. The cultural difference is objective existence. There are all kinds of differences in the cultural orientation, traditional customs, behavioral norms, values and ways of thinking and so on for different ethnic groups and different countries. These differences must be reflected in the carrier of culture, language. When described the same objective thing using different language, it will show the different cultural background. At Learning and using the non-mother-tongue, loading cultural 
knowledge must produce cognitive differences. In real life, people often make mistakes in cross-cultural communication because of the misunderstanding or misusing words. The multiple intelligences theory can help students understand the differences between cognitive and way of and thinking.

On the basis of the multiple intelligences theory, try to reform the metallurgical technology professional English. The reform attempts carried on in three aspects, such as teaching contents selection, teaching means and teaching method. The teaching contents were centered in the production process of iron and steel enterprises, which is started from the beneficiation of iron ores and its end is the steel rolling. The multimedia technology was used in the teaching. The real pictures and simulated dynamic diagrams belonged to the metallurgical equipments and production processes are combined to deepen the understanding of students. The group learning and target teaching had been applied to teaching practice.

The above reform attempts have achieved a certain effects on professional English teaching of metallurgy technology major, and hoped to give some inspirations to all educators for their teaching mode reform.

\section{Teaching Contents Selection}

Teaching contents selection is the key link. The original contents have some problems, such as too monotonous, poor professional pertinence, knowledge lack of advanced and cutting-edge. In order to keep the teaching contents are pertinence, scientific and advanced, the teaching materials choose in the professional papers and the latest academic works, and combined with the manufacturing process of iron and steel complex. As Figure 1 shown, the modern iron and steel production process usually includes iron making, steel making, secondary metallurgy, continuous casting and steel rolling. As characteristic, the knowledge of ferroalloys is added in the teaching materials.

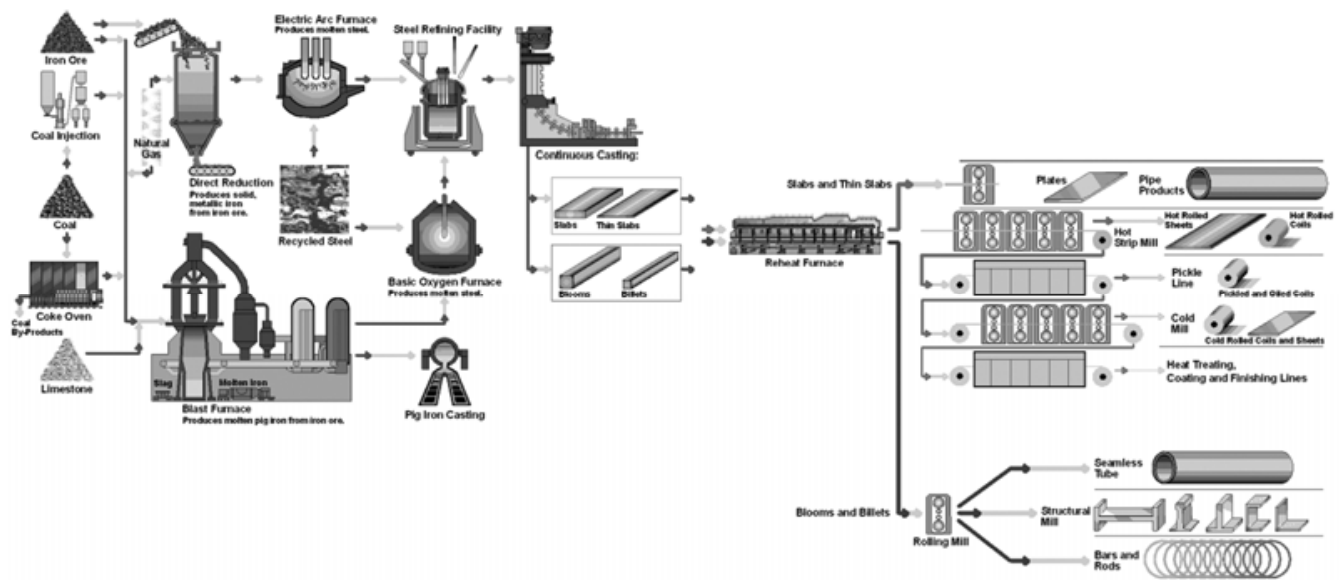

Fig. 1. Modern iron and steel production process

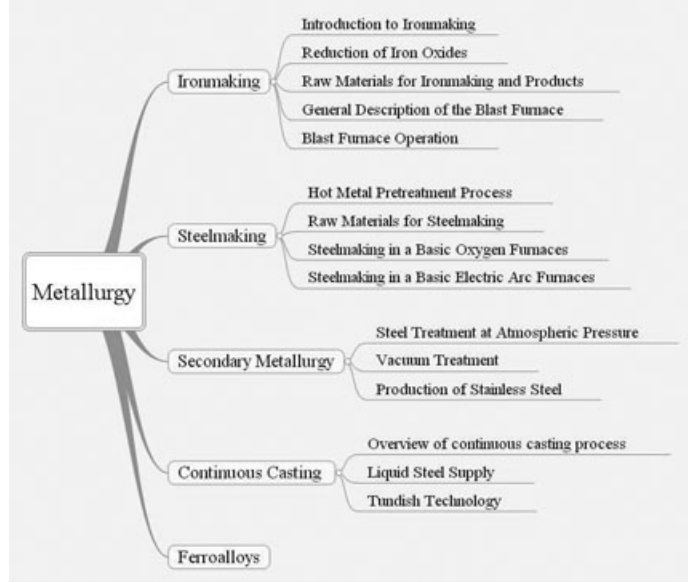

Fig. 2. The directory of self-designed teaching material 
The directory of self-designed teaching material is shown in figure 2. If according to the basic principles, the hot metal pretreatment and secondary refining all belong to treatment outside the furnace. In fact, the hot metal pretreatment is arranged in the front of the steel making and the refining is arranged after the steel making. This arrangement is in line with the factory process.

In every part of teaching contents, the teaching materials are mainly consisted by raw materials, products, principles, equipments and process. In addition, the new techniques are also introduced.

\section{Reform on Teaching Means}

In recent years, multimedia technology has been utilized to replace the traditional blackboard in the classroom. The study shows that the multimedia learning environment can enhance the teaching and learning processes and facilitate the development of pupils' creative responses at English learning.

By taking advantages of multimedia technology, the professional English teaching can combine with the colorful pictures of equipments and the animations of the produce process to cultivate the learning for English words, grammatical structures, and sentences. A page of PPT for professional English teaching is shown in figure 3 (a). The scene photo, the pictures of real product and the principle diagram are all together to assist to explain the meaning of English.

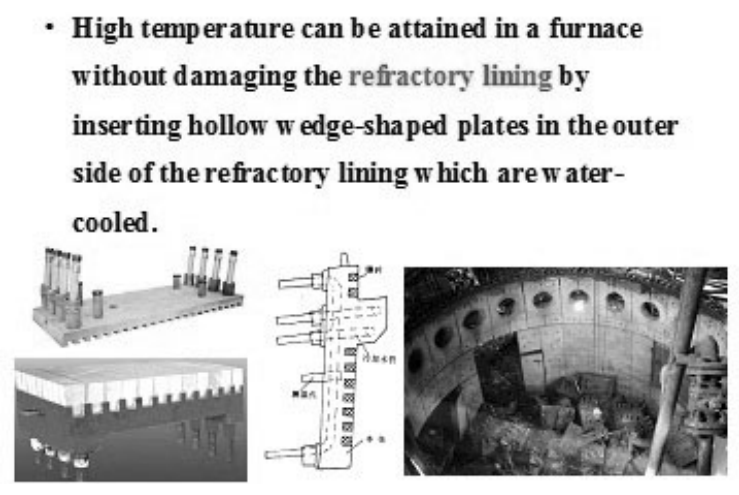

(a) A PPT page which showed the scene photo, pictures of real product and the principle diagram

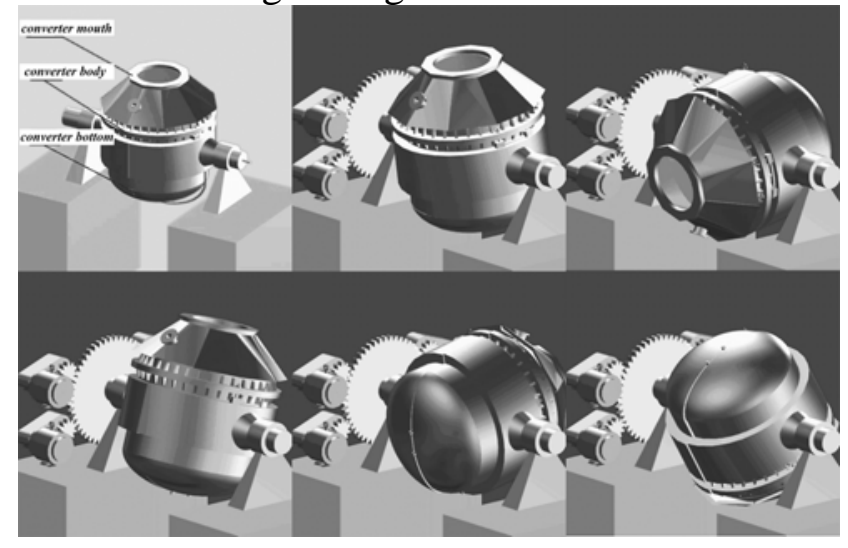

(b) A PPT page which is the simulated diagram of converter tilting process

Fig. 3. Pages of PPT for professional English teaching

The screenshots of, which is simulated by three dimensional animation technologies, are shown in figure 3 (b). When the teacher translated the description of the converter tilting device, at the same time the animation demonstration is shown to students. By this way, the students can easier to understand the expression in English.

The teaching time of professional English is the semester which is later than that of specialized courses. This makes the professional English easier to understand. The professional knowledge is the "bridge" to learn the skill or ability of language expression, clarification of the concept and concepts of collision and so on under another culture background. The final achievement is obtaining required professional information by English as tool. On the other hand, during professional English teaching, the professional knowledge can be reviewed, and the understanding of the knowledge deepens.

But there are many problems in English teaching with multimedia. For example, some teachers change the screen speed quickly, ignoring the students' visual perception totally [4]. So teachers should pay attention to design the content on each screen and control the playback speed.

\section{Reform of Teaching Method}

The task-based approach is introduced to teach professional English. Task-based Approach is the latest development results of western English education and also the latest development of the communicative approach, laying stress on learning by doing [5]. The students are divided into groups which number is equal. At the beginning of class time, the text is divided into several parts as task. Different task was assigned to different groups. Then some times is given to these groups to 
analysis and translate their own text together. Finally a representative is chooses by his group to explain the text for all students. If the effect of explain is good, the whole group would receive awarded marks.

The team members have different characteristics, someone maybe good at words, other one maybe good at grammar and another one maybe good at expression in front of peoples. When completing a common, they can express their special skill respectively, and reduce the difficult of complete the task alone.

By this way, the center of classroom transfers from the teacher to the students. Arouse the enthusiasm of the students to learn. At the same time, cultivate the cooperation ability of students.

Task-based learning can be very effective at intermediate levels and beyond, and the methodology requires a change in the traditional teacher's role. The teacher does not introduce and present language or interfere or help during the task cycle. The teacher is an observer during the task phase and becomes a language informant only during the language focus stage.

Based on all above reforms, the effect of metallurgical technology professional English is improved. For example, the English-Chinese translation ability of students is enhanced. Compared with two test results, the pass rate raised from $70 \%$ to $87 \%$.

\section{Conclusion}

This article introduced reform attempts, which based on the multiple intelligences theory, in teaching methods on metallurgical technology professional English. In order to keep the teaching contents are pertinence, scientific and advanced, the teaching materials choose in the professional papers and the latest academic works, and combined with the manufacturing process of iron and steel complex. Replacing traditional educational methods by the multimedia technology increased the vitality of the courses. The task-based approach was used to change the "teacher-centered" teaching mode into a "student-centered" one. The above reform attempts have achieved a certain effects on professional English teaching of metallurgy technology major, and hoped to give some inspirations to all educators for their teaching mode reform.

\section{Acknowledgement}

This work was supported by the teaching team of Liao Ning Institute of Science Technology, namely Practice and Innovation Ability Training System Construction for Applied Talents of Metallurgical Engineering.

\section{References}

[1] Erchun Chen, Jie Liu. Applying Multimedia Technology to the Teaching and Learning of College English in China: Problems and Solutions[J]. Journal of Information Technology and Application in Education. 20121 (3) 108-111.

[2] Howard Gardner. Frames of Mind: The theory of Multiple Intelligences. New York: Basic Books. 1983.

[3] Howard Gardner. Multiple Intelligences: The Theory in Practice. New York: Basic Books. 1993.

[4] Zefen Zhang. Studies on Multimedia English Teaching from Students' Angle of View[J], National Conference on Information Technology and Computer Science. 2012 1046-1049.

[5] Ling Jiang. Task-based Approach in College English Teaching of Digital-based Context[J]. I. J. Modern Education and Computer Science. 2010 (1) 32-39. 